Sensors 2003, 3, 350-360

\title{
sensors
}

ISSN 1424-8220

(C) 2003 by MDPI

http://www.mdpi.net/sensors

\section{A Novel Hydrogen Peroxide Sensor via the Direct Electrochemistry of Horseradish Peroxidase Immobilized on Colloidal Gold Modified Screen-printed Electrode}

\author{
Xiaoxing $\mathrm{Xu}^{1,2}$, Songqin Liu ${ }^{1}$ and Huangxian $\mathrm{Ju}^{1, *}$ \\ ${ }^{1}$ Department of Chemistry, State Key Laboratory of Coordination Chemistry, Institute of Chemical \\ Biology, Nanjing University, Nanjing 210093, China. Fax: +86-25-3593593. Tel: +86-25-3593593 \\ ${ }^{2}$ Department of Chemistry, Changshu College of Jiangsu, Changshu 215500, China \\ *Author to whom correspondence should be addressed. E-mail: hxju@nju.edu.cn
}

Received: 02 August 2003 / Accepted: 25 August 2003 / Published: 11 September 2003

\begin{abstract}
The direct electrochemistry of horseradish peroxidase (HRP) immobilized on a colloidal gold modified screen-printed carbon electrode (HRP-Au-SPCE) and its application as a disposable sensor were studied. The immobilized HRP displayed a couple of stable and well-defined redox peaks with a formal potential of $-0.338 \mathrm{~V}$ (vs. SCE) and a heterogeneous electron transfer rate constant of $(0.75 \pm 0.04) \mathrm{s}^{-1}$ in $0.1 \mathrm{M} \mathrm{pH} 7.0$ PBS. It showed a highly thermal stability, fast amperometric response and an electrocatalytic activity to the reduction of hydrogen peroxide $\left(\mathrm{H}_{2} \mathrm{O}_{2}\right)$ without the aid of an electron mediator. The biosensor exhibited high sensitivity, good reproducibility, and long-term stability for the determination of $\mathrm{H}_{2} \mathrm{O}_{2}$ with a linear range from $0.8 \mu \mathrm{M}$ to $1.0 \mathrm{mM}$ and a detection limit of $0.4 \mu \mathrm{M}$ at $3 \sigma$. The variation coefficients are $2.7 \%$ and $2.3 \%$ for over 10 successive assays at the $\mathrm{H}_{2} \mathrm{O}_{2}$ concentrations of 8.0 and $20 \mu \mathrm{M}$, respectively. The $K_{M}^{a p p}$ for $\mathrm{H}_{2} \mathrm{O}_{2}$ sensor was determined to be $1.3 \mathrm{mM}$.
\end{abstract}

Keywords: Screen-printed electrodes, Horseradish peroxidase, Electrocatalysis, Colloidal gold,

Amperometric sensors 


\section{Introduction}

The determination of hydrogen peroxide is becoming practical importance in chemical, biological, clinic and many other fields. Many methods such as titrimetry, UV-vis spectrophotometry and electrochemistry have been developed for this purpose [1-3]. Among these methods, the amperometric biosensors based on the direct electron transfer between an electrode and the immobilized enzyme/protein is especially promising because of its simplicity and high sensitivity [4-17]. Horseradish peroxidase (HRP), a prototypical hemeprotein peroxidase (FW ca. 44000), is one of the most widely used enzymes for analytical purposes and biosensors [4,5,7-9,11,12,14,17]. This technique has good sensitivity and accuracy, but at the same time, they suffer from some shortcomings. In the case of the covalent binding of enzymes to solid surfaces like membranes or other solid supports, the procedure needs several steps for the preparation of an adequate functional group on the solid support, and the enzymatic activity decreases to some extent during the covalent cross-linking of the enzyme with mediator [17]. Incorporation of enzyme within electropolymerized polymers or carbon paste, a large of enzyme was not utilized, caused the waste of expensive biocatalyst. Moreover, the substrate electrodes used in above biosensors are not convenient to be automatic and miniaturization. Thus, it was necessary to develop new devices with high sensitivity, rapid response, reliable result, low cost and small size. This objective can be achieved by combining the advantageous features of colloidal gold adsorption and screen-printed technology.

Screen-printing is a standard technology in electronics and has been used to produce disposable electrochemical sensors. Various modifiers such as mediators [18,19], enzymes [20], metal particles [21] have been conveniently added into the printing ink to improve the selectivity and sensitivity of the screen-printed carbon electrodes (SPCE). Colloidal gold is an extensively used metal colloid, which has been used for study of direct electrochemistry of proteins such as HRP [11,12,14], cytochrome c [13,22], and hemoglobin $[15,16]$. This work prepares a colloidal gold nanoparticles modified SPCE by incorporating colloidal gold nanoparticles into carbon ink. HRP is absorbed on the electrode surface to study its direct electron transfer at the modified SPCE. Similar to sol-gel/hydrogel [7] and DNA [23] films casted on pyrolytic graphite electrodes (PGE), the incorporated colloidal gold nanoparticles provide an environment similar to that of redox enzymes in native systems and give the enzyme molecules more freedom in orientation, thus reducing the insulating property of the enzyme shell for the direct electron transfer and facilitating the electron transfer through the conducting tunnels of colloidal gold [24]. The adsorbed HRP displays a high affinity to $\mathrm{H}_{2} \mathrm{O}_{2}$, which produces a novel biosensor and allows a quick detection of $\mathrm{H}_{2} \mathrm{O}_{2}$ down to $0.4 \mu \mathrm{M}$.

\section{Experimental}

\section{Reagents and Materials}

Horseradish peroxidase (E.C.1.11.1.7, RZ >3.0, A>250 units/mg) was obtained from Sigma (USA). $5.0 \mathrm{mg} \mathrm{mL}^{-1} \mathrm{HRP}$ solution was prepared by dissolving $5.0 \mathrm{mg} \mathrm{HRP}$ in the mixture of $400 \mu$ phosphate buffer solution ( $\mathrm{pH}$ 7.0) and $100 \mu$ dimethyl sulfoxide and stored at a temperature of $4{ }^{\circ} \mathrm{C}$ as stock solution. $\mathrm{HAuCl}_{4} \bullet 3 \mathrm{H}_{2} \mathrm{O}$ was purchased from Aldrich (Deisenhofen, Germany). Polyvinyl chloride (PVC) was obtained from Shanghai Chemical Reagent Co. Graphite powder $(<325$ mesh, Johnson Matthey), colloidal gold solution and cellulose diacetate (Shanghai Chemical Reagent Co.) were used 
for preparation of carbon ink. Colloidal gold nanoparticles with diameter of $24 \pm 2 \mathrm{~nm}$ were prepared and stored according to literatures [14,25]. Cellulose diacetate stock solution was prepared by dissolving 1.0 $\mathrm{g}$ cellulose diacetate in $100 \mathrm{~mL} \mathrm{1:1} \mathrm{hexamethylene-acetone.} \mathrm{All} \mathrm{other} \mathrm{chemicals} \mathrm{were} \mathrm{of} \mathrm{analytical}$ reagent grade. Phosphate buffer solutions $(0.1 \mathrm{M})$ with various $\mathrm{pH}$ values were prepared by mixing stock standard solutions of $\mathrm{K}_{2} \mathrm{HPO}_{4}$ and $\mathrm{KH}_{2} \mathrm{PO}_{4}$ and adjusting the $\mathrm{pH}$ with $0.1 \mathrm{M} \mathrm{H}_{3} \mathrm{PO}_{4}$ or $\mathrm{NaOH}$. All solutions were prepared with deionized water of $18 \mathrm{M} \Omega$ purified from a Milli-Q purification system.

\section{Configuration of hydrogen peroxide sensor}

The colloidal gold modified screen-printed carbon electrode was prepared by using a screen-printed technology as follows. Silver ink was firstly printed onto PVC substrate to form conducing track. This surface was washed thoroughly with $\mathrm{NaOH}$ solution and deionized water. $10 \mathrm{mg}$ of pretreated graphite powder was mixed thoroughly with $20 \mu \mathrm{l}$ colloidal gold solution. After evaporation of water in a desiccator for three hours, $30 \mu \mathrm{l}$ cellulose diacetate solution was added to the mixture to obtain colloidal gold modified screen-printed carbon ink (Au-SPC). As a comparison, $10 \mathrm{mg}$ of graphite powder was mixed thoroughly with $30 \mu \mathrm{l}$ cellulose diacetate solution without the presence of colloidal gold nanoparticle to obtain screen-printed carbon ink (SPC). The resulting inks were then printed onto above silver conducting tracks to form colloidal gold modified screen-printed carbon electrode (Au-SPCE) and screen-printed carbon electrode (SPCE). The electrode was insulated by overlaying a silicone rubber layer, only exposing conductive terminal and the working surface with the area of $3 \times 3 \mathrm{~mm}^{2}$. The HRP-SPCE and HRP-Au-SPCE were prepared by dropping $5 \mu \mathrm{l}$ of HRP solution onto the SPCE and $\mathrm{Au}-\mathrm{SPCE}$, respectively. The modified electrodes were rinsed with ethanol and water and stored at $4{ }^{\circ} \mathrm{C}$.

\section{Electrochemical measurements}

Electrochemical experiments were carried out with a BAS-100A electrochemical analyzer at room temperature $(20 \pm 2)^{\circ} \mathrm{C}$. A three-electrode system comprising a prepared working electrode, a platinum wire as auxiliary electrode and a saturated calomel electrode (SCE) as reference was employed for all electrochemical experiments. The real geometry area of the working electrode was determined to be $0.11 \mathrm{~cm}^{2}$ by the slope of plot of the anodic peak current of $1.0 \mathrm{mM} \mathrm{K}_{3}\left[\mathrm{Fe}(\mathrm{CN})_{6}\right]$ in $0.1 \mathrm{M} \mathrm{KCl}$ vs. the square root of scan rate. All experimental solutions were deoxygenated by bubbling highly pure nitrogen for 20 min and maintained under nitrogen atmosphere during the course of the experiment.

\section{Results and Discussion}

\section{Electrochemical properties of HRP immobilized on colloidal gold modified screen-printed electrode}

The electrochemical behavior of HRP immobilized on the Au-SPCE was studied using cyclic voltammetry. The HRP-Au-SPCE showed a couple of stable and well-defined redox peaks at $-290 \pm 3$

and $-377 \pm 3 \mathrm{mV}$ at $50 \mathrm{mV} \mathrm{s}^{-1}$ (curve $\mathrm{d}$ in Fig. 1), while no peak was observed at both SPCE (curve a in Fig. 1) and Au-SPCE (curve b in Fig. 1). The presence of gold colloid resulted in a decrease in the background current. Obviously, the response of the HRP-Au-SPCE was attributed to the redox reaction 


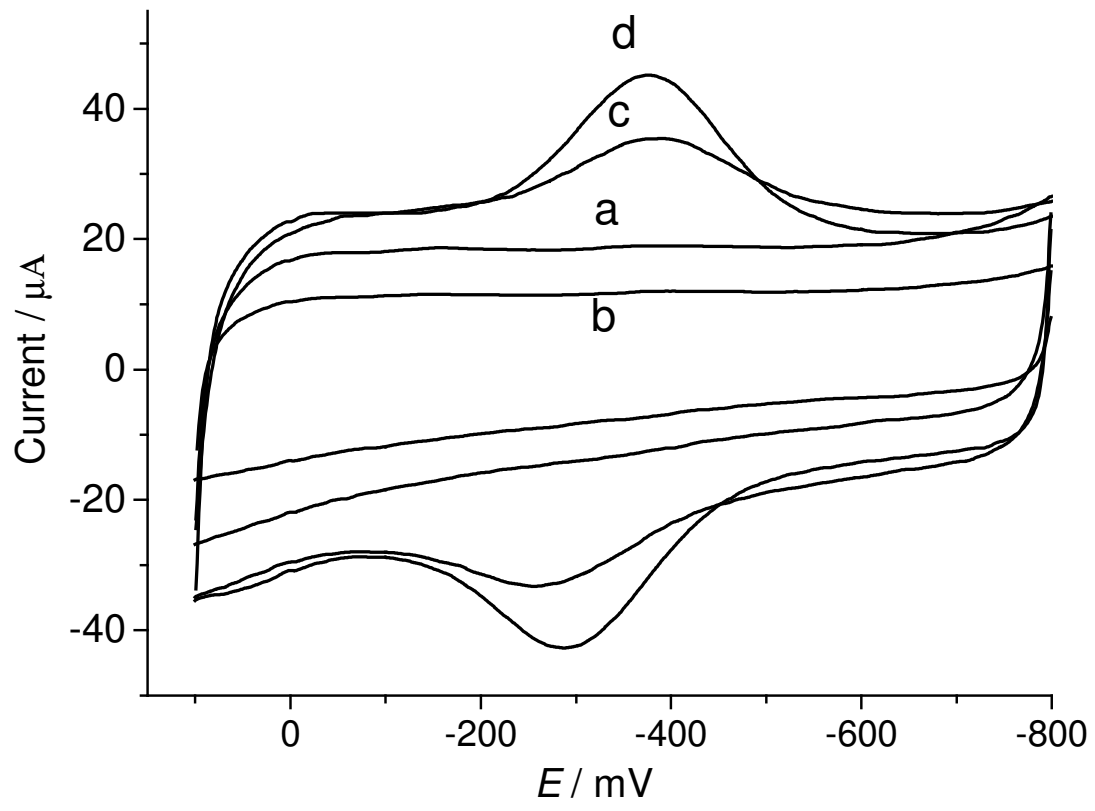

Figure 1. Cyclic voltammograms of SPCE (a), Au-SPCE (b), HRP-SPCE (c) and HRP-Au-SPCE (d) in $0.1 \mathrm{M} \mathrm{pH} 7.0$ phosphate buffer at $50 \mathrm{mV} \mathrm{s}^{-1}$.

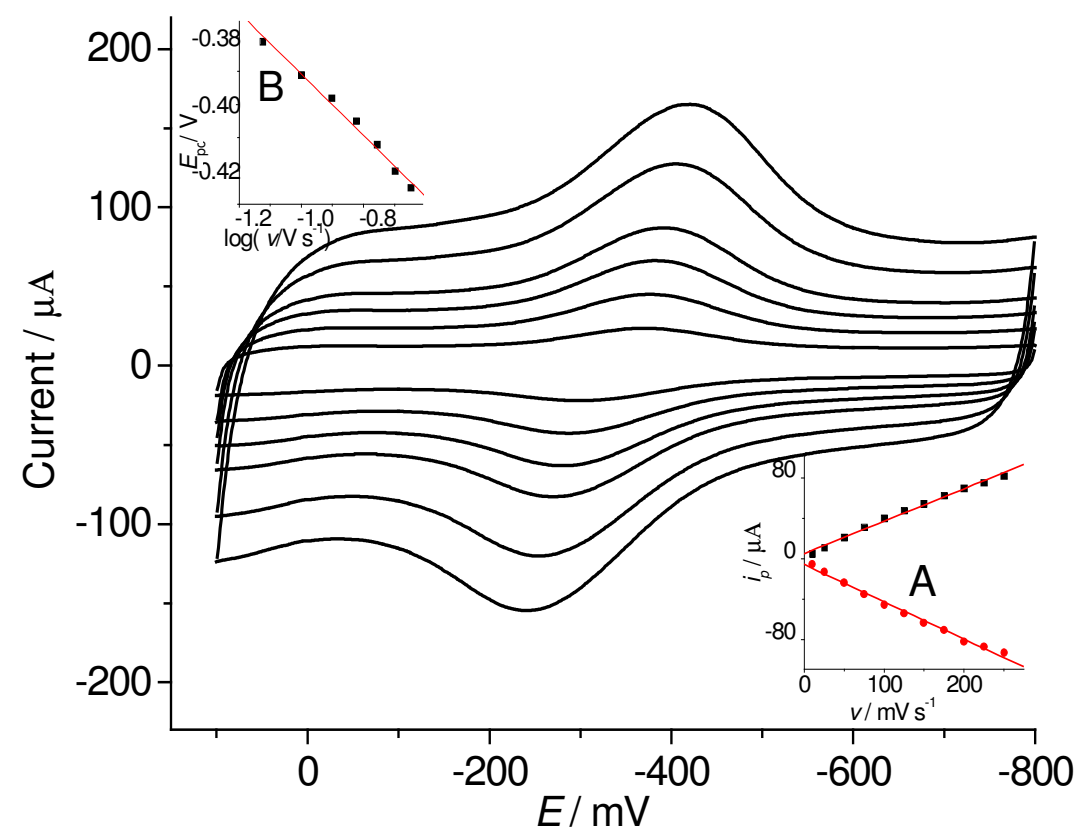

Figure 2. Cyclic voltammograms of HRP-Au-SPCE in $0.1 \mathrm{M} \mathrm{pH} 7.0 \mathrm{PBS}$ at 25, 50, 75, 100, 150 and $200 \mathrm{mV} \mathrm{s}^{-1}$ (from inner to outer). Insets: plots of peak currents vs. scan rate (A) and plots of anodic peak potential vs. $\log v(\mathrm{~B})$. 
of the electroactive centers of HRP. On the other hand, the HRP-SPCE (curve $\mathrm{c}$ in Fig. 1) also displayed a couple of redox peaks of HRP. But the reduction peak current was 2.1 times smaller than that of the HRP-Au-SPCE (curve $d$ in Fig. 1). Thus, the presence of colloidal gold played an important role in accelerating the electron transfer between HRP and the electrode. The formal potential of the $\mathrm{Fe}^{\mathrm{III} / \mathrm{II}}$ couple in HRP-Au-SPCE calculated from the average of anodic and cathodic peak potentials at $\mathrm{pH} 7.0$ was $-338 \pm 3 \mathrm{mV}$ (vs. SCE) at $50 \mathrm{mV} \mathrm{s}^{-1}$, which was closer to $-0.22 \mathrm{~V}$ of native HRP in solution ${ }^{\text {[26] }}$ than the formal potential of $-0.377 \mathrm{~V}$ for the HRP entrapped within a solid matrix at a pyrolytic graphite electrode ${ }^{[27]}$, and equal to $-(0.346 \pm 0.002) \mathrm{V}$ of our previous results [14], suggesting that the most HRP molecules preserved their native structure after the adsorption procedure.

Fig. 2 shows the CV curves of the HRP-Au-SPCE at different scan rates. With an increasing scan rate ranging from 10 to $300 \mathrm{mV} \mathrm{s}^{-1}$ both redox peak currents and peak-to-peak separation increased. The redox peak currents were proportional to the scan rate (inset A in Fig. 2), indicating typical of the surface-controlled quasi-reversible process.

From the slope of the plot of anodic peak potential versus the logarithm of scan rate (inset B in Fig. $2)$, the charge transfer coefficient $\alpha$ of $0.64(n=1)$ could be obtained. The peak-to-peak separations at $40,80,120,160,200$, and $250 \mathrm{mV} \mathrm{s}^{-1}$ were $77,100,132,152,179$ and $197 \mathrm{mV}$, respectively. Thus, the average heterogeneous electron transfer rate constant $k_{\mathrm{s}}$, estimated according to the model of Laviron [28] with the formula $k_{\mathrm{s}}=m n F v / R T$ where $\mathrm{m}$ is a parameter related to the peak-to-peak separation, was $(0.75 \pm 0.04) \mathrm{s}^{-1}$.

\section{Effect of solution $\mathrm{pH}$ and temperature on direct electron transfer of immobilized HRP}

Cyclic voltammograms of HRP-Au-SPCE in PBS showed a strong dependence on solution $\mathrm{pH}$ (Fig. 3). All changes in the peak potentials and currents with solution $\mathrm{pH}$ were reversible in the $\mathrm{pH}$ range from 3.5 to 9.2, that was, the same cyclic voltammograms could be obtained if the electrode was transferred from a solution with a different $\mathrm{pH}$ value to its original solution. An increase in solution $\mathrm{pH}$ caused a negative shift in both cathodic and anodic peak potentials. Plot of the formal potential versus $\mathrm{pH}$ (from 3.5 to 9.2) (inset in Fig. 3) showed a line with a slope of $-43.5 \mathrm{mV} \mathrm{pH}^{-1}$ (R=0.996), which was close to the expected value of $-57.8 \mathrm{mV} / \mathrm{pH}$ for a reversible proton-coupled single electron transfer at $291.15 \mathrm{~K}$, indicating that one proton participated in the electron transfer process.

Thermal stability is a measure of the ability of the biosensor to withstand elevations in temperature [29]. The thermal stability of the biosensor was evaluated by increasing the cell temperature and recording cyclic voltammograms after keeping the corresponding temperature for $20 \mathrm{~min}$. The cathodic peak current of the HRP-Au-SPCE increased with an increasing temperature from $10{ }^{\circ} \mathrm{C}$ to $70{ }^{\circ} \mathrm{C}$ (Fig. 4), displaying an expected Arrhenius-type temperature dependence. Meanwhile the maximum peak current appeared at $37{ }^{\circ} \mathrm{C}$ at HRP-SPCE, and when increasing the cell temperature up to $55^{\circ} \mathrm{C}$ no peak was observed, implying denaturation of the immobilized HRP. The improvement of the thermal stability of HRP-Au-SPCE was attributed to the presence of the colloidal gold nanoparticles. The immobilized HRP on colloidal gold nanoparticles enhanced greatly the thermal stability due to the unusual conformational rigidity in this nonpolar binding environment [29]. 


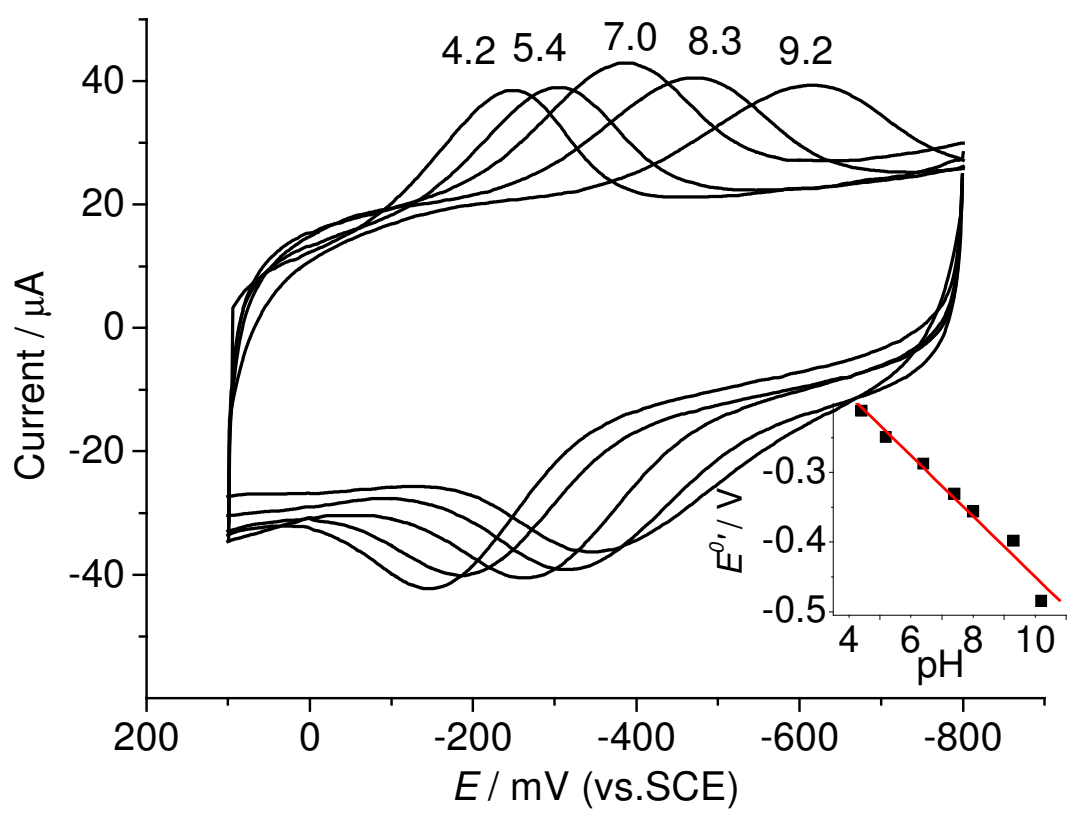

Figure 3. Cyclic voltammograms of HRP-Au-SPCE in PBS with different pHs at $50 \mathrm{mV} \mathrm{s}$. Inset: effect of $\mathrm{pH}$ on the formal potential

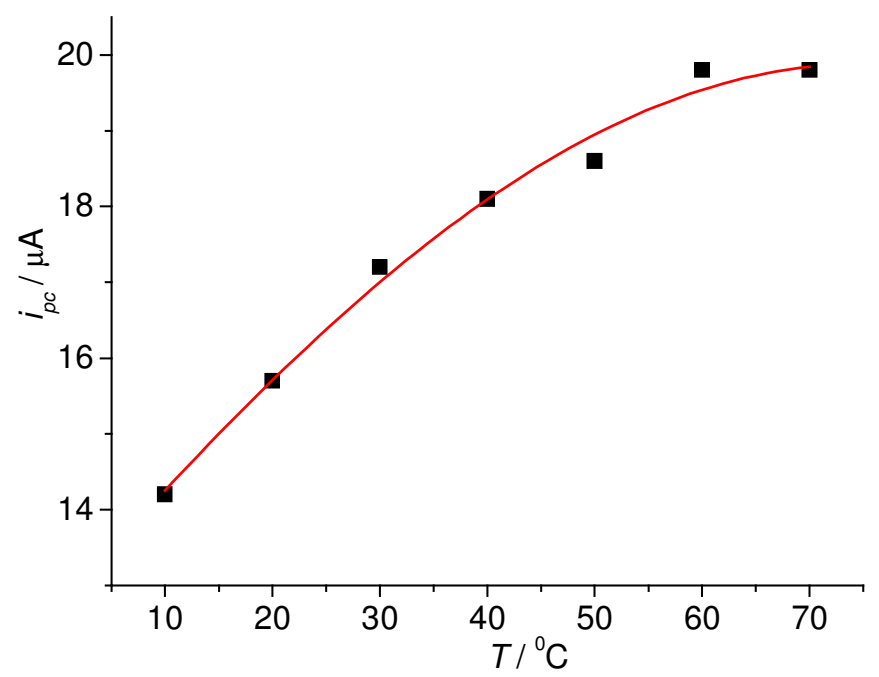

Figure 4. Effect of temperature on cathodic peak current of HRP-Au-SPCE in pH 7.0 PBS

\section{Amperometric response of the $\mathrm{HRP}-\mathrm{Au}$-SPCE to $\mathrm{H}_{2} \mathrm{O}_{2}$}

The cyclic voltammograms of the HRP-Au-SPCE and Au-SPCE in pH 7.0 PBS containing different concentrations of $\mathrm{H}_{2} \mathrm{O}_{2}$ were shown in Fig. 5. Upon addition of $\mathrm{H}_{2} \mathrm{O}_{2}$ to the electrochemical cell the reduction peak current of the immobilized HRP increased and the anodic peak current decreased, while this phenomenon was not observed at a bare SPCE or the Au-SPCE, indicating a typical electrocatalytic 


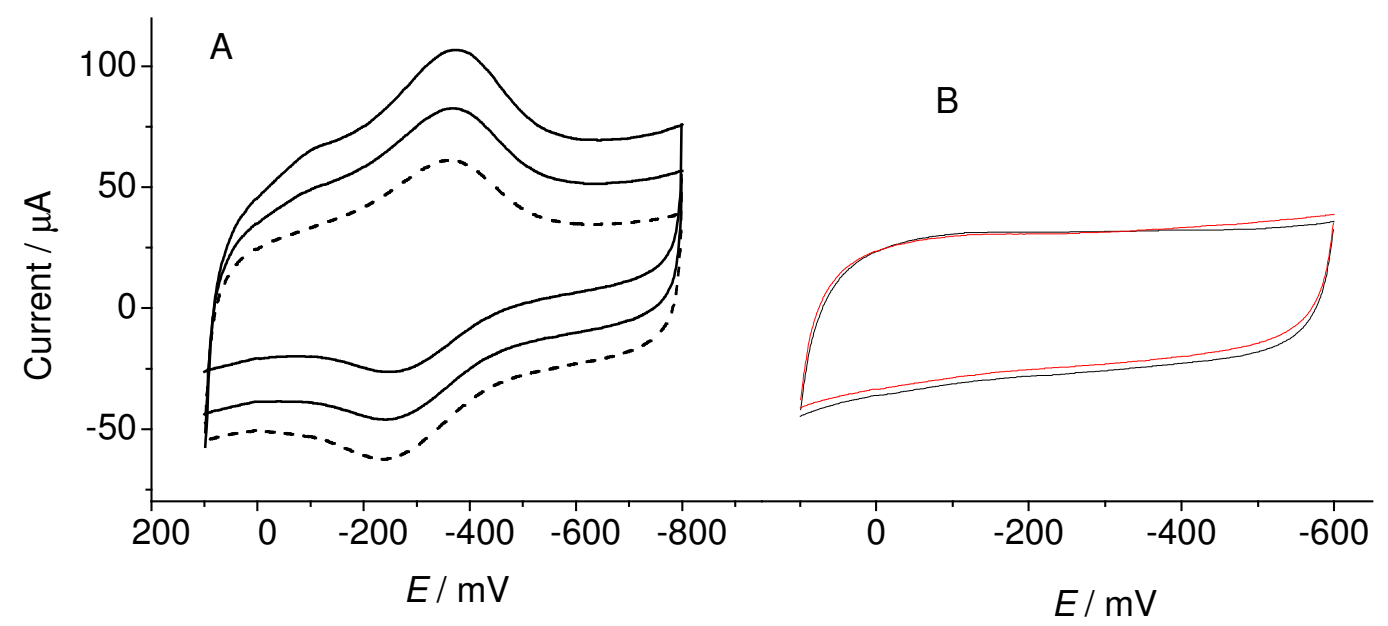

Figure 5. Cyclic voltammograms of HRP-Au-SPCE (A) and Au-SPCE (B) in $0.1 \mathrm{M}$ pH 7.0 PBS containing 0,40 and $120 \mu \mathrm{M} \mathrm{H}_{2} \mathrm{O}_{2}$ (from bottom to top) at $50 \mathrm{mV} \mathrm{s}^{-1}$.

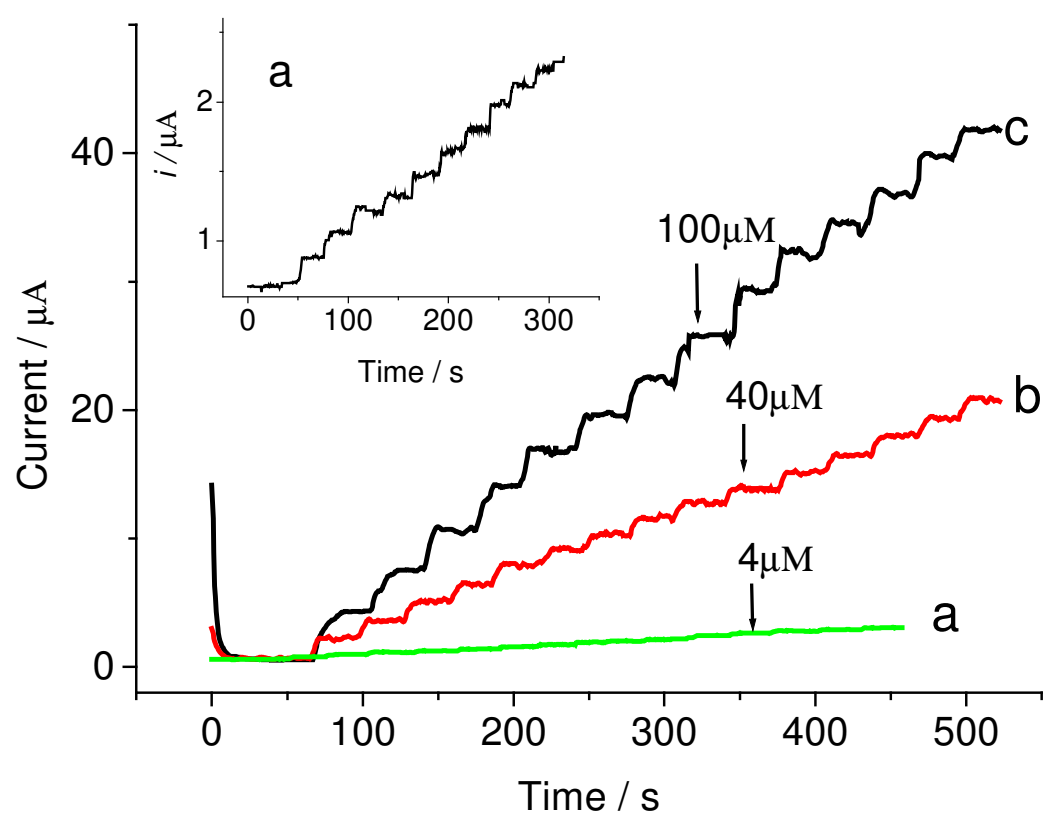

Figure 6. Typical steady-state response of the sensor with an increasing $\mathrm{H}_{2} \mathrm{O}_{2}$ concentration of $4 \times 10^{-6}$ $\mathrm{M}$ (a and inset A), $4 \times 10^{-5} \mathrm{M}(\mathrm{b})$ and $1 \times 10^{-4} \mathrm{M}(\mathrm{c})$ for each step at $-0.4 \mathrm{~V}$

behavior to the reduction of $\mathrm{H}_{2} \mathrm{O}_{2}$. Furthermore, the reduction peak current increased with the increasing $\mathrm{H}_{2} \mathrm{O}_{2}$ concentration. The electrocatalytic process could be expressed as follows [25]: 


$$
\begin{aligned}
& \mathrm{H}_{2} \mathrm{O}_{2}+\mathrm{HRP}_{\text {red }} \rightarrow \mathrm{HRP}_{\text {ox }}+\mathrm{H}_{2} \mathrm{O} \\
& \mathrm{HRP}_{\mathrm{ox}}+2 \mathrm{e}^{-} \rightarrow \mathrm{HRP}_{\text {red }}
\end{aligned}
$$

Fig. 6 illustrates a typical current-time plot of the sensor upon successive addition of $4 \times 10^{-6} \mathrm{M}$ (curve a and inset $\mathrm{A}$ in Fig. 6), $4 \times 10^{-5} \mathrm{M}$ (curve b in Fig. 6), and $1 \times 10^{-4} \mathrm{M}$ (curve c in Fig. 6) of $\mathrm{H}_{2} \mathrm{O}_{2}$ to $0.1 \mathrm{M}$ pH 7.0 PBS under stirring, respectively. Upon addition of successive aliquots of $\mathrm{H}_{2} \mathrm{O}_{2}$ to PBS, the response occurring immediately was attributed to the reduction of $\mathrm{HRP}_{\mathrm{ox}}$ that was produced from the quick reaction between the immobilized $\mathrm{HRP}$ and $\mathrm{H}_{2} \mathrm{O}_{2}$. Fig. 7 shows the calibration curve of the sensor. The calibration range of $\mathrm{H}_{2} \mathrm{O}_{2}$ was $8 \times 10^{-7} \mathrm{M}$ to $2.2 \times 10^{-3} \mathrm{M}$. The linear response range of $\mathrm{H}_{2} \mathrm{O}_{2}$ was from $8 \times 10^{-7}$ to $1.0 \times 10^{-3} \mathrm{M}$ with a correlation coefficient of 0.999 and a detection limit of $0.4 \mu \mathrm{M}$ at $3 \sigma$. The linear slope gave a sensitivity of $306.7 \mu \mathrm{A} \mathrm{mM}^{-1} \mathrm{~cm}^{-2}$. The linear range of this sensor was wider than those of $2 \times 10^{-5}$ to $2.6 \times 10^{-3} \mathrm{M}$ at HRP-CPE [30], $10^{-6}$ to $2.63 \times 10^{-3} \mathrm{M}$ at peroxidase electrodes [31], $4 \times 10^{-6}$ to $9 \times 10^{-5} \mathrm{M}$ at $\mathrm{HRP} /$ poly (AMFc) enzyme electrode [32], and $4 \times 10^{-7}$ to $1 \times 10^{-4} \mathrm{M}$ at Prussian blue modified carbon [33], $5 \times 10^{-6}$ to $5 \times 10^{-5} \mathrm{M}$ at gold and platinum screen printed electrodes [34].

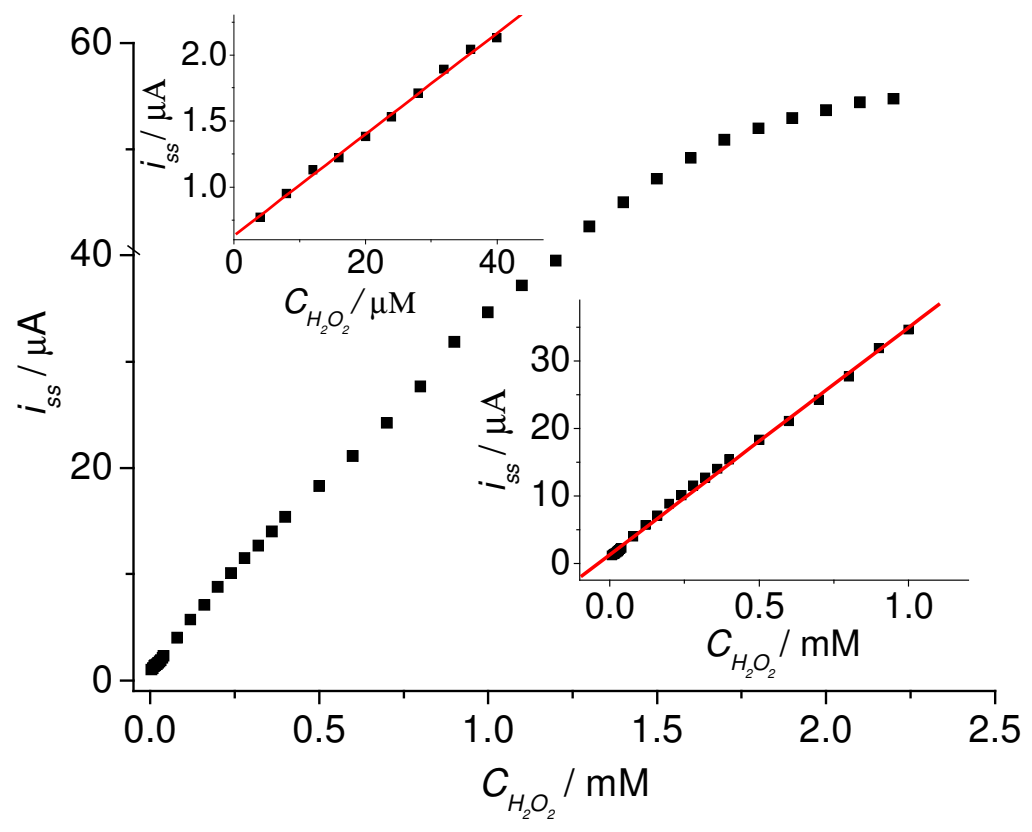

Figure 7. Calibration curve of HRP-Au-SPCE for successive addition of $\mathrm{H}_{2} \mathrm{O}_{2}$ in $0.1 \mathrm{M} \mathrm{pH} 7.0 \mathrm{PBS}$. Insets: linear calibration curves.

When the concentration of $\mathrm{H}_{2} \mathrm{O}_{2}$ was higher than $1.0 \mathrm{mM}$, a response platform was observed, showing a characteristic of the Michaelis-Menten kinetic mechanism. The apparent Michaelis-Menten constant $\left(K_{M}{ }^{a p p}\right)$, which gave an indication of the enzyme-substrate kinetics, could be obtained from the electrochemical version of the Lineweaver-Burk equation [35]. The $K_{M}{ }^{a p p}$ was determined by analysis of the slope and intercept of the plot of the reciprocals of the steady-state current versus $\mathrm{H}_{2} \mathrm{O}_{2}$ concentration (Fig. 8). The $K_{M}^{a p p}$ value of the HRP-Au-SCPE was $1.3 \pm 0.3 \mathrm{mM}$, which was lower than 
those of $4.8 \mathrm{mM}$ at HRP-CPE [30], $4.6 \mathrm{mM}$ at PB-SPCE [33] and $2.3 \mathrm{mM}$ at HRP/Au colloid self-assemble monolayer electrode [36]. Thus, the sensor had a higher affinity to $\mathrm{H}_{2} \mathrm{O}_{2}$.

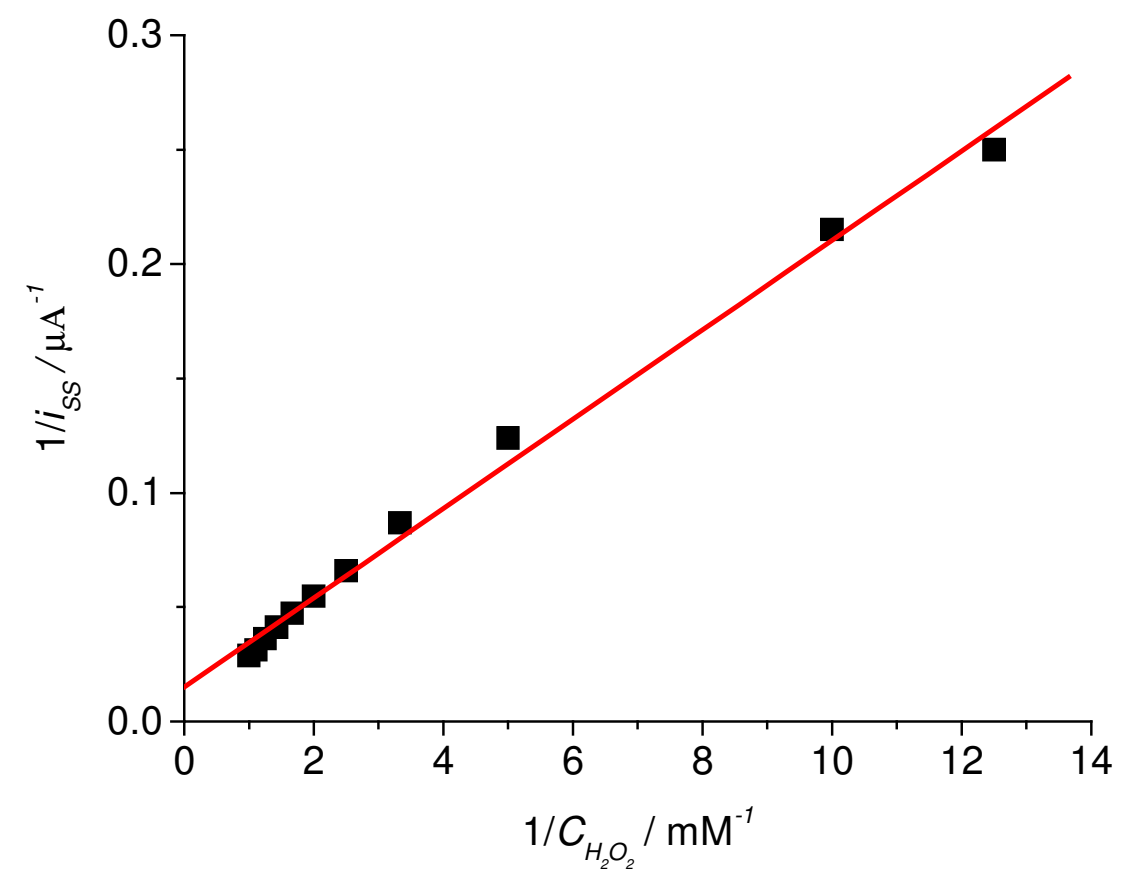

Figure 8. Lineweaver-Burk plot

\section{Analytical performance of $\mathrm{H}_{2} \mathrm{O}_{2}$ Sensor}

The sensor had a fast amperometric response to the reduction of $\mathrm{H}_{2} \mathrm{O}_{2}$. It attained $95 \%$ of the steady-state currents in less than $10 \mathrm{~s}$ during the calibration range of $\mathrm{H}_{2} \mathrm{O}_{2}$. The reproducibility of the catalytic current response of the disposable sensor was tested at the $\mathrm{H}_{2} \mathrm{O}_{2}$ concentration of 8.0 and 20 $\mu \mathrm{M}$. The sensor showed an acceptable reproducibility with the relative standard deviations of $2.7 \%$ and $2.3 \%$ for over ten successive assays, respectively. After stored for one month at $4{ }^{\circ} \mathrm{C}$ or two week at room temperature, the sensor retained over $90 \%$ or $72 \%$ of its initial current response respectively, indicating good storage stability.

The accuracy of the sensor was evaluated by determining the recoveries after addition of $\mathrm{H}_{2} \mathrm{O}_{2}$ ranging from 4.0 to $80 \mu \mathrm{M}$ into $0.1 \mathrm{M} \mathrm{pH}$ 7.0 PBS and the results obtained were given in Table 1 . The sensor exhibited satisfactory results with an average recovery of $98.3 \%$ to $101.2 \%$.

The coexistence ions and compounds were tested to exam the possible interference with the detection of $\mathrm{H}_{2} \mathrm{O}_{2}$. If the addition of given ion caused a current change of $5 \%$ or more, it was considered to interfere with the determination of $\mathrm{H}_{2} \mathrm{O}_{2}$. The detection results indicated that $\mathrm{Ca}^{2+}, \mathrm{Mg}^{2+}, \mathrm{Co}^{2+}, \mathrm{CO}_{3}{ }^{2-}$ and catechol at the concentrations of 25 times, $\mathrm{I}^{2-}, \mathrm{S}^{2-}$ and urate at the concentrations of 5 times, ascorbate and dopamine at the concentrations of 4 times did not interfere with the determination of 10 $\mu \mathrm{M} \mathrm{H}_{2} \mathrm{O}_{2}$. Thus, this sensor had a good selectivity. 
Table 1. The recoveries determined at HRP-Au-SPCE modified electrode

\begin{tabular}{rcc}
\hline $\begin{array}{r}\text { Added } \\
(\mu \mathrm{M})\end{array}$ & $\begin{array}{r}\text { Found } \\
(\mu \mathrm{M})\end{array}$ & $\begin{array}{r}\text { Recovery } \\
(\%)\end{array}$ \\
\hline 4.0 & 3.93 & 98.3 \\
8.0 & 7.89 & 98.6 \\
12.0 & 12.14 & 101.2 \\
20.0 & 20.07 & 100.4 \\
40.0 & 39.92. & 99.8 \\
80.0 & 80.16 & 100.2 \\
\hline
\end{tabular}

\section{Real Sample Analysis}

Hydrogen peroxide may be used as a preservative or decolourant in food industry and additive in production of cosmetic. The sufficient sterilization is considered at $0.03 \%$ hydrogen peroxide in milk and $0.08 \%$ in bean products. Moreover, the leftover amount did not inspect. The determination of $\mathrm{H}_{2} \mathrm{O}_{2}$ in milk sample was performed on the sensor utilizing standard addition method. After the current response was determined in $5.0 \mathrm{ml}$ of $0.1 \mathrm{M} \mathrm{pH} 5.0 \mathrm{PBS}$ containing sample of $500 \mu 1,1.36 \times 10^{-3} \mathrm{mg} \mathrm{ml}^{-1}$ of $\mathrm{H}_{2} \mathrm{O}_{2}$ solutions was successively added to the system for standard addition determination. The concentration of $\mathrm{H}_{2} \mathrm{O}_{2}$ in milk sample was found to be $(1.38 \pm 0.05) \times 10^{-3} \mathrm{mg} \mathrm{ml}^{-1}(\mathrm{n}=5)$.

\section{Conclusions}

Horseradish peroxidase can be effectively immobilized on colloidal gold modified screen-printed carbon electrode to produce a fast direct electron transfer. The immobilized HRP maintains its bioactivity and native structure. The immobilized horseradish peroxidase displays a high affinity to hydrogen peroxide, which allows producing a novel $\mathrm{H}_{2} \mathrm{O}_{2}$ sensor for a fact measurement of $\mathrm{H}_{2} \mathrm{O}_{2}$. The resulting sensor displays a high sensitivity and a wide linear range from $8 \times 10^{-7}$ to $1.0 \times 10^{-3} \mathrm{M}$, and can efficiently exclude the interference of commonly coexisted ions and compounds.

\section{Acknowledgments}

This project was supported by the National Natural Science Foundation of China (No.20275017, 90206037), the Specialized Research Funds for the Excellent Young Teachers from Chinese Ministry of Education, the Science Foundation of Jiangsu (No.BS2001063) and the Key Project of Cancer Institute of Jiangsu Province.

\section{References}

1. Vogel, A.I. Textbook of Quantitative chemical Analysis Longman: U.K. 1989, p372.

2. Matsubara, C.; Kawamoto, N; Takamala, K. Analyst 1992, 117, 1781.

3. Wollenberger, U.; Wang, J.; Ozsoz, M.; Gonzalez Romero, E.; Scheller, F. Bioelectrochem. Bioenerg. 1991, 26, 287. 
4. Wang, B.; Li, B.; Wang, Z.; Xu, G.; Wang, G.; Dong, S. Anal. Chem. 1999, 71, 1935.

5. Wang, J.; Ciszewski, A.; Naser, N. Electroanalysis 1992, 4, 777.

6. Kim, E.J.; Haruyama, T.; Yanagida, Y.; Kobatake, E.; Aizawa, M. Anal. Chim. Acta 1999, 394, 225.

7. Wang, B.; Zhang, J.; Cheng, G.; Dong, S. Anal. Chim. Acta 2000, 407, 111.

8. El-Essi, F.A.; Abu Zuhri, A.Z.; Al-Khalil, S.I.; Abdel-Latif, M.S. Talanta 1997, 44, 2051.

9. Razola, S.S.; Aktas, E.; Virê, J.-C.; Kauffmann, J.-M. Analyst 2000, 125, 79.

10. Mondal, M.S.; Fuller, H.; Hirst, J.; Armstrong, F.A. J. Inorg Biochem. 1995, 59, 454.

11. Xiao, Y.; Ju, H.X.; Chen, H.Y. Anal. Chim. Acta 1999, 391, 73.

12. Xiao, Y.; Ju, H.X.; Chen, H.Y. Anal. Biochem. 2000, 278, 22.

13. Ju, H.X.; Liu, S.Q.; Ge, B.; Lisdat, F.; Scheller, F.W. Electroanalysis 2002, 14, 141.

14. Liu, S.Q.; Ju, H.X. Anal. Biochem. 2002, 307, 110.

15. Gu, H.Y.; Yu, A.M.; Chen, H.Y. J. Electroanal. Chem. 2001, 516, 119.

16. Fan, C.; Wang, H.; Sun, S.; Zhu, D.; Wagner, G.; Li, G. Anal. Chem. 2001, 73, 2850.

17. Ruan, C.; Feng, Y.; deng, C.J. Anal. Chem. 1998, 70, 1721.

18. Cass, A.E.G.; Davis, G.; Francis, G.D.; Hill, H.A.O.; Aston, W.J.; Higgins, I.J.; Plotkin, E.V.; Scott, L.D.L.; Turner, A.P.F. Anal, Chem. 1984, 56, 667.

19. Gilmartin, M.A.T.; Ewen, R.J.; Hart, J.P. J. Electroanal. Chem. 1996, 401, 127.

20. Abass, A.K.; Hart, J.P.; Cowell, D. Sens. Actuators B 2000, 62, 148.

21. Wang, J.; Chen, Q.; Pedrero, M.; Pingarrón, J.M. Anal. Chim. Acta 1995, 300, 111.

22. Brown, K.R.; Fox, A.P.; Natan, M.J. J. Am. Chem. Soc. 1996, 118, 1154.

23. Chen, X.; Ruan, C.; Kong, J.; Deng, J. Anal. Chim. Acta 2000, 412, 89-98.

24. Liu, S.Q.; Leech, D.; Ju, H.X. Anal. Lett. 2003, 36, 1-19.

25. Zhao, J.; Stonchuerner, R. W.; O’Daly, J. P.; Crumbliss, A. L. J. Electroanal. Chem. 1992, 327, 109-119.

26. Harbury, H. A. J. Biol. Chem. 1957, 225, 1009-1024.

27. Ferri, T.; Poscia, A.; Santucci, R. Bioelectrochem. Bioenerg. 1998, 44, 177-181: 45, 221-226.

28. Laviron, E. J. Electroanal. Chem. 1979, 101, 19-28.

29. Wang, J.; Liu, J.; Cepra, G. Anal. Chem. 1997, 69, 3124-3127

30. Li, J.; Tan, S.N.; Ge, H. Anal. Chim. Acta 1996, 335, 137-145.

31. Cosgrove, M.; Moody, G.J.; Thomas, D.R. Analyst 1988, 113, 1811-1815.

32. Mulhandanl, A.; Wang, C.H.L.; Weetall, H.H. Anal. Chem.1995, 67, 94-100.

33. O'Halloran, M.P.; Pravda, M.; Guilbault, G.G. Talanta 2001, 55, 605-611.

34. Mattos, I.L.; Gorton, L.; Ruzgas, T. Biosens. Bioelectron. 2003, 18, 193-200

35. Kamin, R. A.; Willson, G. S. Anal. Chem. 1980, 52, 1198-1205.

36. Gaspar, S.; Zimmermann, H.; Gazaryan, I.; Csoregi, E.; Schuhmann, W. Electroanalysis 2001, 13, 284-288.

Sample Availability: Available from the authors.

(C) 2003 by MDPI (http://www.mdpi.net). Reproduction is permitted for noncommercial purposes. 